\title{
Diagnostic and prognostic role of mean platelet volume and mean platelet volume/platelet ratio in patients with primary malignant bone tumor
}

\author{
Fevzi Coşkun Sökmen, MD1ㅁ, Coşkun Ulucaköy, MD²D \\ 1'Department of Internal Medicine, Dr. Abdurrahman Yurtaslan Oncology Training and Research Hospital, Ankara, Turkey \\ ${ }^{2}$ Department of Orthopedics and Traumatology, Dr. Abdurrahman Yurtaslan Oncology Training and Research Hospital, Ankara, Turkey
}

Primary malignant bone tumors originate from bone tissue and are generally rarer than secondary bone tumors. Primary bone tumors account for about $0.2 \%$ of all neoplasms. ${ }^{[1]}$ Osteosarcoma, chondrosarcoma, and Ewing's sarcoma are the most common primary malignant tumors of the bone, representing 35\%, $30 \%$, and $16 \%$ of all cases, respectively. ${ }^{[2]}$ These tumors are diagnosed clinically, radiologically, and histopathologically, and there are many factors that affect prognosis. ${ }^{[3,4]}$ In the diagnosis and treatment of bone tumors, studies on blood values for diagnostic and prognostic purposes have been increasing in recent years. ${ }^{[5]}$

Inflammation has a significant role in tumor progression and metastasis, and platelets (PLTs) also play an essential role in inflammation. ${ }^{[6]}$ Some

Received: May 18, 2020

Accepted: August 11, 2020

Published online: January 06, 2021

Correspondence: Coşkun Ulucaköy, MD. SBÜ Dr. Abdurrahman Yurtaslan Onkoloji Eğitim ve Araştırma Hastanesi Ortopedi ve Travmatoloji Kliniği, 06105 Yenimahalle, Ankara, Türkiye.

E-mail: coskunulucakoy@gmail.com

Doi: $10.5606 /$ ehc.2021.76357

Citation: Sökmen FC, Ulucaköy C. Diagnostic and prognostic role of mean platelet volume and mean platelet volume/platelet ratio in patients with primary malignant bone tumor. $\mathrm{Jt}$ Dis Relat Surg 2021;32(1):198-203.

(C2021 All right reserved by the Turkish Joint Diseases Foundation

This is an open access article under the terms of the Creative Commons Attribution-NonCommercial License, which permits use, distribution and reproduction in any medium, provided the original work is properly cited and is not used for commercial purposes (http://creativecommons.org/licenses/by-nc/4.0/).

\section{ABSTRACT}

Objectives: This study aims to investigate the diagnostic and prognostic role of mean platelet volume (MPV) and MPV/platelet (PLT) ratio in primary malignant bone tumors.

Patients and methods: We retrospectively investigated patients with primary malignant bone tumors between January 2010 and January 2019 and included 109 patients (69 males, 40 females; mean age: $41.9 \pm 17.9$ years; range 15 to 86 years) in the study. A total of 107 healthy volunteers (61 males, 46 females; mean age: 47 years; range 19 to 61 years) who donated blood to the blood center of our hospital in 2019 formed the control group. Demographic features, MPV, PLT counts, mortality, and recurrence records of the patients were obtained from archives.

Results: Of the 109 patients, 11 were diagnosed with Ewing's sarcoma, 52 with chondrosarcoma, and 46 with osteosarcoma. The tumor was located on the right in $56 \%$ of patients and on the lower extremity in $59.6 \%$ of patients. The recurrence rate was $41.3 \%$ in the patient group. Of the 109 patients, $17(15.6 \%)$ resulted in exitus at follow-up. The mean PLT value of the patient group was significantly higher than the control group (289,440 vs. 247,299 , $\mathrm{p}<0.001)$. The median MPV and MPV/PLT ratios were statistically significantly lower in the patient group than in the control group ( 8.3 vs. $10.5, \mathrm{p}<0.001$ and 0.032 vs. $0.043, \mathrm{p}<0.001$, respectively). The MPV, PLT count, and MPV/PLT ratio were not associated with mortality and recurrence. The cut-off value was determined as $>9.25 \mathrm{fL}$ for MPV (sensitivity $=74 \%$, specificity $=85 \%$, positive likelihood ratio $=4.96$, positive predictive value $=83.4 \%$, and negative predictive value $=76.5$ ).

Conclusion: Consequently, MPV and MPV/PLT ratios can be used as a diagnostic support parameter in primary malignant bone tumors, but have no prognostic value.

Keywords: Bone tumor, mean platelet volume, platelet count.

PLT indices are related with prognosis of various cancers, including breast cancer, laryngeal cancer, colorectal cancer, pancreatic cancer, gastric cancer, and non-small cell lung cancer. ${ }^{[7]}$ Platelet count and mean platelet volume (MPV) are two main characteristics to evaluate PLT activation. ${ }^{[8]}$ Mean 
platelet volume is a PLT volume index and there are several opinions regarding the decrease of MPV in neoplastic processes. According to one of these, the inflammatory condition associated with carcinoma is thought to lead to excessive PLT consumption and, consequently, to a recently confirmed MPV reduction. ${ }^{[9,10]}$

To the best of our knowledge, there is no study investigating the relationship between primary malignant bone tumors and MPV and MPV/PLT ratio in the literature. Therefore, in this study, we aimed to investigate the diagnostic and prognostic role of MPV and MPV/PLT ratio in primary malignant bone tumors.

\section{PATIENTS AND METHODS}

We retrospectively investigated patients with primary malignant bone tumors between January 2010 and January 2019 at Dr. Abdurrahman Yurtaslan Oncology Training and Research Hospital. Demographic features, MPV, PLT counts, mortality, and recurrence records of the patients were obtained from archives. All MPV and PLT values of patients were recorded before biopsy or any treatment (surgery, neoadjuvant radiotherapy or chemotherapy). A total of 109 patients (69 males, 40 females; mean age: $41.9 \pm 17.9$ years; range 15 to 86 years) diagnosed with Ewing's sarcoma ( $n=11)$, chondrosarcoma $(n=52)$, and osteosarcoma $(n=46)$ were included. The MPV and PLT values of 107 healthy volunteers (61 males, 46 females; mean age: 47 years; range 19 to 61 years) who referred to our hospital blood center in 2019 and were similar in age and sex to the patient group constituted the control group. Patients with hematological disease, infection, and autoimmune disease were excluded. The study protocol was approved by the Dr. Abdurrahman Yurtaslan Oncology Training and Research Hospital Ethics Committee (Approval No: 2020-06/635). A written informed consent was obtained from each participant. The study was conducted in accordance with the principles of the Declaration of Helsinki.

\section{Statistical analysis}

Statistical analysis was performed using the IBM SPSS version 22.0 software (IBM Corp., Armonk, NY, USA). Descriptive statistics were presented as numbers and percentages for categorical variables and mean \pm standard deviation, median (min-max) for continuous variables. Normal distributions for continuous variables were assessed with visual (histograms and probability graphics) and analytic methods (Kolmogorov-Smirnov and Shapiro-Wilk test). In the data that do not fit the normal distribution, Mann-Whitney $U$ test was used for comparison analysis between the two independent groups and the independent sample t-test was used for the data that fit the normal distribution. Comparison analyses for categorical variables between independent groups were performed by chi-square test. Diagnostic and prognostic values of pre-treatment MPV, PLT count and MPV/PLT ratio were assessed using receiver operating curve (ROC) analysis. Results presented following ROC analysis included area under curve (AUC) and cut-off values, sensitivity and specificity of these cut-off values, likelihood ratio (LHR), positive predictive value (PPV), and negative predictive value (NPV). ${ }^{[1,12]}$ A $p$ value of $<0.05$ was considered statistically significant.

\section{RESULTS}

The tumor was located on the right in $56 \%$ of patients and on the lower extremity in $59.6 \%$ of patients. The recurrence rate was $41.3 \%$ in the patient group. Of the 109 patients in the patient group, $17(15.6 \%)$ resulted in exitus at follow-up (Table I). The age and sex distributions of the control and patient groups were similar ( $p=0.871$ and $p=0.345$, respectively). The mean PLT value of the patient group was significantly higher than the control group $(289,440$ vs. $247,299, \mathrm{p}<0.001)$

\begin{tabular}{|c|c|c|}
\hline \multicolumn{3}{|c|}{$\begin{array}{l}\text { TABLE I } \\
\text { Basal demographics of malignancies }(n=109)\end{array}$} \\
\hline Characteristic & $\mathrm{n}$ & $\%$ \\
\hline \multicolumn{3}{|c|}{ Pathology of malignancies } \\
\hline Ewing's sarcoma & 11 & 10.1 \\
\hline Chondrosarcoma & 52 & 47.7 \\
\hline Osteosarcoma & 46 & 42.2 \\
\hline \multicolumn{3}{|l|}{ Side } \\
\hline Right & 62 & 56.9 \\
\hline Left & 47 & 43.1 \\
\hline \multicolumn{3}{|l|}{ Localization } \\
\hline Upper limb & 28 & 25.7 \\
\hline Lower limb & 65 & 59.6 \\
\hline Pelvis & 13 & 11.9 \\
\hline Clavicle & 1 & 0.9 \\
\hline Scapula & 2 & 1.8 \\
\hline \multicolumn{3}{|l|}{ Recurrence } \\
\hline Yes & 45 & 41.3 \\
\hline No & 64 & 58.7 \\
\hline \multicolumn{3}{|l|}{ Exitus } \\
\hline Yes & 17 & 15.6 \\
\hline No & 92 & 84.4 \\
\hline
\end{tabular}




\begin{tabular}{|c|c|c|c|c|c|c|c|c|c|c|c|}
\hline \multicolumn{12}{|c|}{$\begin{array}{l}\text { TABLE II } \\
\text { Evaluation of patient and control groups }(n=216)\end{array}$} \\
\hline & \multicolumn{5}{|c|}{ Patients $(n=109)$} & \multicolumn{5}{|c|}{ Controls $(n=107)$} & \multirow[b]{2}{*}{$p$} \\
\hline & $\mathrm{n}$ & $\%$ & Mean $\pm S D$ & Median & Min-Max & $\mathrm{n}$ & $\%$ & Mean $\pm S D$ & Median & Min-Max & \\
\hline Age (year) & & & & 40 & $15-86$ & & & & 47 & $19-61$ & $0.871^{*}$ \\
\hline Sex & & & & & & & & & & & $0.345 \dagger$ \\
\hline Female & 40 & 36.7 & & & & 46 & 43.0 & & & & \\
\hline Male & 69 & 63.3 & & & & 61 & 57.0 & & & & \\
\hline PLT count & & & $289,440 \pm 8,409$ & & & & & $247,299 \pm 5,141$ & & & $<0.001 \ddagger$ \\
\hline MPV & & & & 8.3 & $6.4-11.7$ & & & & 10.5 & $8.1-14.0$ & $<0.001^{*}$ \\
\hline MPV/PLT ratio & & & & 0.032 & $0.01-0.07$ & & & & 0.043 & $0.02-0.08$ & $<0.001^{*}$ \\
\hline
\end{tabular}

(Table II). The median MPV and MPV/PLT ratios were statistically significantly lower in the patient group than in the control group ( 8.3 vs. $10.5, \mathrm{p}<0.001$ and 0.032 vs. $0.043, \mathrm{p}<0.001$, respectively). Since the rates of MPV, PLT count, and MPV/PLT showed significant differences in patient/control group comparison, we evaluated the diagnostic predictability of all three parameters for bone tumors via ROC analysis (Figure 1). The highest significant AUC value was obtained for MPV (AUC=0.894) and then for MPV/PLT ratio (AUC=0.786) (Table III). The AUC value obtained for PLT count was statistically significant but weak (AUC=0.657).
The cut-off value was determined as $>9.25 \mathrm{fL}$ for MPV (sensitivity $=74 \%$, specificity $=85 \%,+\mathrm{LHR}=4.96$, $\mathrm{PPV}=83.4 \%$, and NPV=76.5). When the cut-off values obtained for all three parameters and the sensitivity, specificity, +LHR, PPV, and NPV values of these cut-off values were analyzed, values of MPV 9.25 and below were better than the other two parameters (MPV/PLT ratio and PLT count) in the diagnostic approach for the disease (sensitivity $=74 \%$, specificity $=85 \%, \quad+\mathrm{LHR}=4.96, \quad \mathrm{PPV}=83.4 \%$, and NPV=76.5). The predictability of MPV, PLT count, and MPV/PLT ratio for mortality and recurrence was evaluated by ROC analysis (Table IV). The AUC

\begin{tabular}{|c|c|c|c|c|c|c|c|c|c|}
\hline Statistical par & s of $v$ & us diagnos & pproz & $\begin{array}{r}\text { TA } \\
\text { es for pre } \\
(n\end{array}$ & $\begin{array}{l}\text { E III } \\
\text { ictive value of } p \\
\text { 16) }\end{array}$ & perative MPV, & LT co & and MF & LT ratio \\
\hline & AUC & $95 \% \mathrm{Cl}$ & $p$ & Cut-off & Sensitivity (\%) & Specificity (\%) & +LHR & PPV (\%) & NPV (\%) \\
\hline PLT & 0.657 & $0.584-0.730$ & $<0.001$ & $\geq 257.5$ & 60.6 & 63.6 & 1.66 & 62.9 & 61.3 \\
\hline MPV/PLT ratio & 0.786 & $0.725-0.846$ & $<0.001$ & $\leq 0.033$ & 66.1 & 85 & 4.42 & 81.8 & 71.1 \\
\hline MPV & 0.894 & $0.853-0.934$ & $<0.001$ & $\leq 9.25$ & 74.3 & 85 & 4.96 & 83.4 & 76.5 \\
\hline
\end{tabular}

\section{TABLE IV}

Predictability of mortality and recurrence for PLT count, mean PLT volume and mean PLT volume/PLT ratio using receiver operating curve analysis $(n=107)$

\begin{tabular}{|c|c|c|c|c|c|c|}
\hline & \multicolumn{2}{|c|}{ Mortality } & \multirow[b]{2}{*}{$p$} & \multicolumn{2}{|c|}{ Recurrence } & \multirow[b]{2}{*}{$p$} \\
\hline & AUC & $95 \% \mathrm{Cl}$ & & AUC & $95 \% \mathrm{Cl}$ & \\
\hline PLT & 0.561 & $0.395-0.727$ & 0.428 & 0.625 & $0.519-0.732$ & 0.027 \\
\hline MPV/PLT ratio & 0.549 & $0.384-0.714$ & 0.526 & 0.591 & $0.483-699$ & 0.107 \\
\hline MPV & 0.505 & $0.352-0.659$ & 0.943 & 0.501 & $0.392-0.610$ & 0.985 \\
\hline
\end{tabular}


(a)

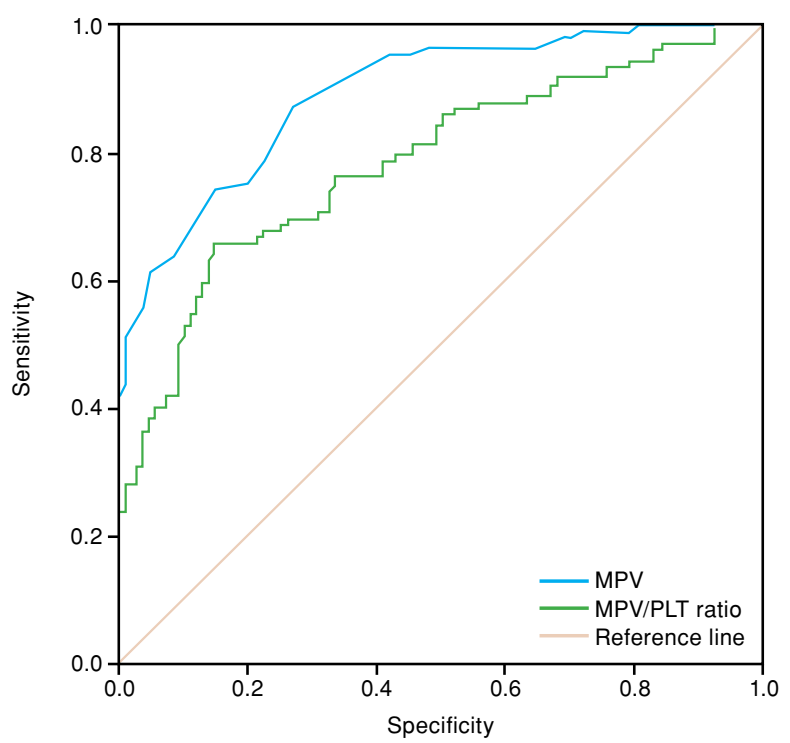

(b)

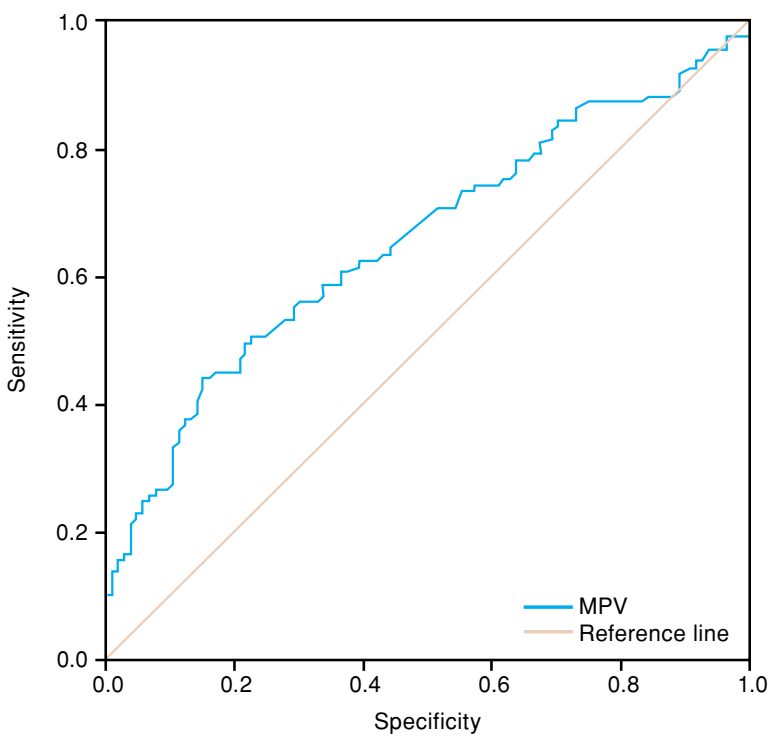

FIGURE 1. Receiver operating characteristic curves for mean PLT volume (a), mean PLT volume/PLT ratio, and PLT (b). (a) Smaller results of mean PLT volume and mean PLT volume/PLT ratio indicate more diagnostic positive test for sarcomas. (b) Larger results of PLT indicate more diagnostic positive test for sarcomas; MPV: Mean platelet volume; PLT: Platelet.

values of all three parameters were below 0.7. The MPV, PLT, and MPV/PLT ratio were not associated with mortality and recurrence.

\section{DISCUSSION}

Measurement of MPV is noninvasive, cheap, and quick, and may therefore serve as a valuable predictor. ${ }^{[7]}$ Our study is the first that examined the relationship between MPV, PLT count, MPV/PLT ratio, and primary malignant bone tumor. The main finding of the study presented is that MPV and MPV/PLT ratio were lower in primary malignant bone tumor patients than in the control group and can be used in diagnosis.

The MPV is a precise measurement of the dimensions calculated by hematological analyzers based on volume distribution during the routine blood morphology test and while MPV ranges from 7.5 to $12.0 \mathrm{fL}$, the percentage of large PLTs should be equal to 0.2 to $5.0 \%$ of the entire PLT population..$^{[7]}$ In physiological conditions, MPV is inversely proportional to the number of PLTs associated with the maintenance of homeostasis and conservation of fixed PLT mass. ${ }^{[13]}$ Therefore, some researchers indicate that MPV should always be assessed together with PLT count as there is a nonlinear inverse relationship between MPV and PLT count. ${ }^{[14]}$ Thus, we have evaluated not only MPV, but also MPV/PLT ratio in this study.
There was a relationship between MPV and cardiac diseases, cerebrovascular ischemia, respiratory, diseases and some rheumatic diseases. ${ }^{[7]}$ In recent years, studies investigating the relationship between MPV and malignancy have been increasing. ${ }^{[15-20]}$ Inagaki et al. ${ }^{[14]}$ in patients with non-small cell lung cancer showed a significant reduction in MPV and MPV/PLT ratio. The authors believe that the decrease in these parameters is caused by inverse nonlinear correlation between PLT count and their volume. Yun et al. ${ }^{[15]}$ demonstrated reduced MPV in renal cell cancer patients compared to healthy volunteers. A study by Kumagai et al. ${ }^{[16]}$ confirmed a lower MPV level in patients with lung cancer compared to healthy subjects in the control group. In addition, Aksoy et al. ${ }^{[17]}$ showed reduced MPV in solid tumors that metastasized to the bone marrow. In this study, we found reduced MPV and MPV/PLT ratio in patients with malignant bone tumor compared to normal healthy volunteers. Therefore, we believe that MPV and MPV/PLT ratio can be used for diagnostic purposes in malignant bone tumors.

There are studies in the literature about the reduction of MPV in neoplastic processes, and there are some hypotheses regarding this situation. The first hypothesis is that the inflammatory condition associated with carcinoma leads to excessive PLT consumption and MPV reduction. ${ }^{[10]}$ Another view 
states that this decrease in MPV may be due to the interference of blood cells into angiogenesis, migration, and invasion of cancer cells. ${ }^{[7]}$ Despite these views, there are publications showing the relationship between malignancies and increased MPV. Kurt et al. ${ }^{[19]}$ suggest that in patients with chronic liver diseases, MPV can be a potential marker of liver cancer. The authors showed that MPV levels in patients with hepatocellular carcinoma were significantly higher compared to patients with chronic hepatitis and healthy subjects. Similarly, Li et al. ${ }^{[20]}$ showed increased MPV in colon cancer patients compared to the normal population. Therefore, we think that further studies are needed to investigate the biological relationship between MPV and cancer.

Although the number of studies that have investigated the biological association between MPV and cancer progression is limited, recent clinical reports demonstrated the negative effect of a low MPV on the prognosis of cancer patients. ${ }^{[14-16]}$ Riedl et al. ${ }^{[21]}$ found a negative relationship between low MPV values and survival in various types of cancer. Similarly, there are publications linking low MPV with poor prognosis in non-small cell lung cancer. ${ }^{[14,16]}$ In this study, no relationship was found between the prognosis of malignant bone tumors and MPV and MPV/PLT ratio. We attribute this to many other factors (treatment methods, distant organ metastases etc.) that may affect prognosis. In addition, the treatment methods of bone tumors included in this study are different and Ewing's sarcoma is a member of sarcoma primitive neuroectodermal tumors (PNET). However, we think that further studies are needed investigating the relationship between prognosis of malignant bone tumors and MPV and MPV/PLT ratio.

This study has some limitations. Smoking status, which may affect the MPV and MPV/PLT ratio, has not been recorded. Similarly, there is no record of drugs considered to be effective on MPV. Another limitation is that malignant bone tumors evaluated in this study had different biological behaviors and treatments. Moreover, this was a single-center retrospective study. Still, our study is valuable since it is the first to investigate the relationship between primary malignant bone tumors and MPV and MPV/PLT ratio. ${ }^{[22]}$

In conclusion, MPV and MPV/PLT ratios can be used as a diagnostic support parameter in primary malignant bone tumors, but have no prognostic value. Given the full availability and accessibility of these indices, more extensive prospective studies are needed to clarify their potential role in primary malignant bone tumors.

\section{Declaration of conflicting interests}

The authors declared no conflicts of interest with respect to the authorship and/or publication of this article.

\section{Funding}

The authors received no financial support for the research and/or authorship of this article.

\section{REFERENCES}

1. Baena-Ocampo Ldel C, Ramirez-Perez E, Linares-Gonzalez LM, Delgado-Chavez R. Epidemiology of bone tumors in Mexico City: retrospective clinicopathologic study of 566 patients at a referral institution. Ann Diagn Pathol 2009;13:16-21.

2. Dai X, Ma W, He X, Jha RK. Review of therapeutic strategies for osteosarcoma, chondrosarcoma, and Ewing's sarcoma. Med Sci Monit 2011;17:RA177-90.

3. Atalay İB, Yılmaz S, Şimşek MA, Ekşioğlu MF, Güngör BŞ. Chondrosarcomas of the phalanges of the hand. Eklem Hastalik Cerrahisi 2018;29:34-9.

4. Öztürk R, Arıkan ŞM, Bulut EK, Kekeç AF, Çelebi F, Güngör BŞ. Distribution and evaluation of bone and soft tissue tumors operated in a tertiary care center. Acta Orthop Traumatol Turc 2019;53:189-94.

5. Yapar A, Ulucaköy C, Sezgin EA, Atalay İB, Ekşioğlu MF. Diagnostic role of neutrophil-to-lymphocyte ratio and monocyte-to-lymphocyte ratio in patients with enchondroma and low-grade chondrosarcoma. Jt Dis Relat Surg 2020;31:286-90.

6. Mezouar S, Frère $C$, Darbousset $R$, Mege D, Crescence L, Dignat-George F, et al. Role of platelets in cancer and cancer-associated thrombosis: Experimental and clinical evidences. Thromb Res 2016;139:65-76.

7. Korniluk A, Koper-Lenkiewicz OM, Kamińska J, Kemona $\mathrm{H}$, Dymicka-Piekarska V. Mean platelet volume (MPV): New perspectives for an old marker in the course and prognosis of inflammatory conditions. Mediators Inflamm 2019;2019:9213074.

8. Zhang H, Liu L, Fu S, Liu YS, Wang C, Liu T, Liu ZP, Wang RT, Yu KJ. Higher platelet distribution width predicts poor prognosis in laryngeal cancer. Oncotarget 2017;8:48138-44.

9. Thompson CB, Jakubowski JA, Quinn PG, Deykin D, Valeri CR. Platelet size and age determine platelet function independently. Blood 1984;63:1372-5.

10. Safak S, Uslu AU, Serdal K, Turker T, Soner S, Lutfi A. Association between mean platelet volume levels and inflammation in SLE patients presented with arthritis. Afr Health Sci 2014;14:919-24.

11. Metz CE. Basic principles of ROC analysis. Semin Nucl Med 1978;8:283-98.

12. Thompson CB, Jakubowski JA. The pathophysiology and clinical relevance of platelet heterogeneity. Blood 1988;72:1-8.

13. Butkiewicz AM, Kemona H, Dymicka-Piekarska V, Matowicka-Karna J, Radziwon P, Lipska A. Platelet count, mean platelet volume and thrombocytopoietic indices in healthy women and men. Thromb Res 2006;118:199-204. 
14. Inagaki N, Kibata K, Tamaki T, Shimizu T, Nomura S. Prognostic impact of the mean platelet volume/platelet count ratio in terms of survival in advanced non-small cell lung cancer. Lung Cancer 2014;83:97-101.

15. Yun ZY, Zhang X, Liu YS, Liu T, Liu ZP, Wang RT, et al. Lower mean platelet volume predicts poor prognosis in renal cell carcinoma. Sci Rep 2017;7:6700.

16. Kumagai S, Tokuno J, Ueda Y, Marumo S, Shoji T, Nishimura $\mathrm{T}$, et al. Prognostic significance of preoperative mean platelet volume in resected non-small-cell lung cancer. Mol Clin Oncol 2015;3:197-201.

17. Aksoy S, Kilickap S, Hayran M, Harputluoglu H, Koca E, Dede DS, et al. Platelet size has diagnostic predictive value for bone marrow metastasis in patients with solid tumors. Int J Lab Hematol 2008;30:214-9.

18. Obuchowski NA. Receiver operating characteristic curves and their use in radiology. Radiology 2003;229:3-8.

19. Kurt M, Onal IK, Sayilir AY, Beyazit Y, Oztas E, Kekilli M, et al. The role of mean platelet volume in the diagnosis of hepatocellular carcinoma in patients with chronic liver disease. Hepatogastroenterology 2012;59:1580-2.

20. Li JY, Li Y, Jiang Z, Wang RT, Wang XS. Elevated mean platelet volume is associated with presence of colon cancer. Asian Pac J Cancer Prev 2014;15:10501-4.

21. Riedl J, Kaider A, Reitter EM, Marosi C, Jäger U, Schwarzinger I, et al. Association of mean platelet volume with risk of venous thromboembolism and mortality in patients with cancer. Results from the Vienna Cancer and Thrombosis Study (CATS). Thromb Haemost 2014;111:670-8.

22. Atik OŞ. Is there something new and interesting in my article? Eklem Hastalik Cerrahisi 2019;30:69. 